\title{
Atrazine dissipation and its impact on the microbial communities and community level physiological profiles in a microcosm simulating the biomixture of on-farm biopurification system
}

\author{
G.R. Tortella ${ }^{a, *}$, R.A. Mella-Herrera ${ }^{a}$, D.Z. Sousa ${ }^{b}$, O. Rubilar ${ }^{a}$, J.J. Acuña ${ }^{a}$, \\ G. Briceño ${ }^{a}$, M.C. Diez ${ }^{\mathrm{a}}$ \\ a Nucleo Científico Tecnológico en Biorecursos, Universidad de La Frontera, Casilla 54-D, Temuco, Chile \\ ${ }^{\mathrm{b}}$ IBB-Institute for Biotechnology and Bioengineering, Centre of Biological Engineering, University of Minho, Campus de Gualtar, 4710-057 Braga, Portugal
}

\section{H I G H L I G H T S}

- Effect of atrazine on microcosm simulating a peat based biomixture of on-biopurification system was evaluated.

- Atrazine dissipation, enzyme activities and microbial communities were assessed.

- Efficient atrazine degradation and short-term inhibitory effect on microbial activity were observed.

- Atrazine did not significantly change the structure of microbial communities.

- We demonstrate the microbiological robustness of peat based biomixture when high atrazine dose is treated.

\section{A R T I C L E I N F O}

\section{Article history:}

Received 29 January 2013

Received in revised form 23 April 2013

Accepted 23 May 2013

Available online $\mathrm{xxx}$

\section{Keywords:}

Microbial community

Pesticides

Biopurification system

Atrazine

\begin{abstract}
A B S T R A C T
The effects of repeated atrazine application ( $40 \mathrm{mg}$ a.i. $\mathrm{kg}^{-1}$ ) on its degradation, microbial communities and enzyme activities were studied in a peat based biomixture composed by straw, soil and peat in the volumetric proportions of 2:1:1 that can be used in on-farm biopurification system. Atrazine removal efficiency was high $(96 \%, 78 \%$ and $96 \%$ ) after each atrazine application and did not show a lag phase. Microbial enzyme activities were reduced significantly with atrazine application but rapidly recovered. Microbial diversity obtained by BiologEcoplate ${ }^{\mathrm{TM}}$ was similar after the first and second atrazine application. However, an inhibitory effect was observed after the third application. After each atrazine application, culturable fungi were reduced, but rapidly recovered without significant changes in culturable bacteria and actinomycetes compared to the control. Denaturing gradient gel electrophoresis (DGGE) patterns demonstrated that microbial community structure remained relatively stable in time when compared to the controls. In conclusion, our results demonstrated that after successive ATZ applications, the peat based biomixture had a good degradation capacity. Moreover, microbiological assays demonstrated the robustness of the peat based biomixture from a microbiological point of view to support pesticide degradation.
\end{abstract}

(c) 2013 Elsevier B.V. All rights reserved.

\section{Introduction}

On farm biopurification systems, commonly known as "biobeds", are a biotechnological tool used to reduce pesticide point source pollution [1]. The principal component is the biomixture [2], which is composed traditionally of straw, peat and soil in a volumetric proportion of 2:1:1. However, some lignocellulosic substrates of the biomixture have been replaced in some countries, for adaptation purposes [3-5]. This composition promotes the

\footnotetext{
* Corresponding author. Tel.: +56 45 325487; fax: +56 45325053 .

E-mail addresses: gonzalo.tortella@gmail.com, gtortell@ufro.cl (G.R. Tortella).
}

development of numerous microorganisms, especially white rot fungi, which can degrade pesticides through extracellular enzymes, e.g., phenoloxidases [2]. Several studies have been reported to examine pesticide biodegradation in the biomixture of a biopurification system [6-12] and in a full-scale biobed model [13,14].

Pesticides are synthesised to inhibit the growth of target microorganisms, but their effects can often be extended to nontarget soil microorganisms as has been well reported in the literature $[15,16]$, causing changes in microbial community structure and soil quality [16-18]. Thus, it is expected that pesticides will also affect the microbial communities in the biomixture of biopurification systems. However, few studies up to now have been presented detailed information on pesticide effect on the microbial 
community structure in a traditional biomixture of biobed system $[2,19]$. Therefore, a better understanding on the dynamics of the microbial communities and enzyme activities in the biomixture after pesticide exposure in this biopurification system is crucial to know if possible changes induced in microbial communities and their activities can influence the pesticide biodegradation and their microbiological sustainability. Research to date suggests that the composition of microbial communities in compost based biomixtures contaminated with pesticides is reduced, but recovery from the effects of pesticides is normally observed over time. For example, Vischetti et al. [9] reported that the microbial biomass (MBC) content in a compost based biomixture composed of vinebranches, urban wastes-garden compost following the addition of chlorpyrifos and metalaxyl negatively affected the MBC, but this was recovered as the pesticide concentration decreased. Similar results regarding the effect different fungicides had on microbial diversity in a modified biomixture consisting of compost and straw were reported by Coppola et al. [20]. Denaturing gradient gel electrophoresis (DGGE) showed a transient change of microbial diversity that was correlated to fungicides application. Recently, Marinozzi et al. [5] reported that the application of three fungicides showed adverse effects in the structure of biomixture microorganisms. However, negative effects were transitory, and recoveries of microbial parameters were observed $60 \mathrm{~d}$ after the pesticide application. However, these effects could be more severe when pesticides are more persistent, applied repeatedly at high concentrations or occur in combination with other toxic compounds [2,7,9,21]. Although Sniegowski et al. [10] reported that in biobed system linuron mineralisation not was affected when the biomixture was exposed to cold period and to pesticide mixture. Interestingly, Sniegowski et al. [10] reported that variations in overall microbial communities in biobed were associated with environmental changes as cold or drought period and not related with pesticide application. Moreover, changes in microbial communities related with pesticide application were observed when specific target bacterial genera were evaluated. In another work, Sniegowski et al. [11] reported that bioaugmentation of on-farm biopurification system with pesticide primed-soils, showed the proliferation of specific microorganisms responsible of the linuron mineralisation. However, it was not clear in the biomixture composed by non-primed soil. In this sense, Bers et al. [12] reported that the presence of linuron in the biomixture could activate important unknown biological mechanism involved in linuron degradation. According to the mentioned above, variation and effects caused by pesticides in the biomixture are just beginnings to be explored.

Atrazine [2-chloro-4-ethylamino-6-isopropylamino-1,3,5triazine] (ATZ) it is a herbicide widely used in agricultural activities in the world to control broadleaf weeds in corn (Zea mays L.) and wheat (Triticum aestivum) production. ATZ has been identified as a moderately persistent pesticide and their movements through environment are key factors influencing its potential to contaminate soil and water [22]. Moreover, ATZ has been reported as one of the major pesticide requiring an important attention and therefore the development of effective methods for decontamination of contaminated matrices $[23,24]$ and little information has been reported in the literature regarding its degradation and their microbiological effects in the biobed system.

Thus, the aim of the present study was to evaluate the impact of ATZ applied repeatedly at high concentrations on microbial functional diversity, microbial communities, enzyme activities and its degradation in a biopurification system background composed by straw:peat:soil in the volumetric proportions of $2: 1: 1$. This biomixture was selected because is widely used in biobed system and little information is reported from microbiological point of view, compared to compost based biomixtures.

\section{Materials and methods}

\subsection{Chemicals}

Analytical standards of ATZ (99\% purity) were purchased from Chem Service (West Chester, USA). The commercial formulation of ATZ (Atranex 50 SC) was obtained from Agan Chemicals Manufacturers Ltd. MBTH (3-methyl-2-benzothiazolinone hydrazone), DMAB (3-(dimethylamino) benzoic acid) were purchased from Aldrich.

\subsection{Biomixture preparation}

The biomixture was prepared by mixing top soil, commercial peat (organic carbon 39.6\%) and winter wheat straw (organic carbon $43 \%$ ) in the volumetric proportions of $1: 1: 2$, respectively. The soil ( $30.7 \%$ sand, $41.8 \%$ silt, $27.4 \%$ clay, organic matter $18 \%$, pH 6.1 ) was collected $(0-20 \mathrm{~cm})$ from the experimental station Maquehue (Andisol Freire series; $38^{\circ} 50^{\prime} \mathrm{S}, 72^{\circ} 41^{\prime} \mathrm{W}$ ) of La Frontera University (Temuco-Chile), which was without an ATZ application history. The straw was cut into small fragments ( $3 \mathrm{~mm}$ ) using a food processor, while the soil and the peat were sieved $(3 \mathrm{~mm})$. The constituents were mixed vigorously and homogenised by hand. The biomixture was placed inside of a polypropylene bag for the maturation process during $150 \mathrm{~d}$ at $25 \pm 2{ }^{\circ} \mathrm{C}$ and the moisture content was adjusted with sterilised distilled water (SDW) to approximately $60 \%$ of its water holding capacity (WHC) and stored. Chemical characterisation is available as supplementary material (Table S1).

\subsection{Biomixture treatment}

After the maturation process, bulk samples $(2.0 \mathrm{~kg})$ of the biomixture were placed into glass containers $(40 \mathrm{~cm} \times 20 \mathrm{~cm} \times 10 \mathrm{~cm}$ deep $)$ in triplicate and artificially contaminated. ATZ was applied with a predetermined volume according to a commercial formulation, which allowed for a proper dilution with SDW to give a certain level of ATZ ( $40 \mathrm{mg}$ a.i. $\mathrm{kg}^{-1}$ ) and to obtain biomixture moisture of $60 \%$ (WHC). The ATZ dose applied was approximately forty-fold above the recommended field dose, to simulate a pesticide spill on the biomixture. The treatments consisted of three successive doses of ATZ at the same concentration on 0,30 and $60 \mathrm{~d}$. A biomixture control received the same amount of SDW without ATZ. Control and treatment were incubated at $25 \pm 2{ }^{\circ} \mathrm{C}$ for $90 \mathrm{~d}$. The biomixture moisture was maintained by regular addition of SDW. At fixed intervals and between each ATZ application, samples of the biomixture were collected for the determination of residual ATZ and biological parameters. Pesticide recovery is available in supplementary material.

\subsection{Enzyme activities}

Dehydrogenase activity (DHA) was calculated using a standard curve using 2,3,5-triphenyltetrazoliumchloride (TTC) as a substrate according to Casida et al. [25]. DHA was expressed as $\mu \mathrm{g}$ TPF produced $\mathrm{g}^{-1} \mathrm{~h}^{-1}$.

Acid and alkaline phosphatase activities were determined according to Tabatabai and Bremmer [26] using p-nitrophenyl phosphate $(0.05 \mathrm{M})$ as a substrate. Phosphatase activities were expressed as $\mu \mathrm{g}$ p-nitrophenol $\mathrm{g}^{-1} \mathrm{~h}^{-1}$ produced.

Phenoloxidase activity was determined using the MBTH/DMAB method proposed by Castillo et al. [27] and Castillo and Torstensson [28].

\subsection{Community level physiological profiles (CLPP)}

CLPPs were assessed by the BiologEcoplate ${ }^{\mathrm{TM}}$ system (Biolog Inc., CA, USA). Microplates containing 96-wells filled with 31 sole 
carbon sources and water blank, all in triplicate, were inoculated according to the method proposed by Fang et al. [29]. Viable cell number was determined using a LIVE/DEAD ${ }^{\circledR}$ BacLight ${ }^{\mathrm{TM}}$ Bacterial Viability Kit (Invitrogen, Carlsbad, CA). Then, $10^{4}$ viable cells were inoculated into each well and incubated at $25 \pm 1{ }^{\circ} \mathrm{C}$. The colour development in each well was monitored at regular time intervals for $74 \mathrm{~h}$ at $590 \mathrm{~nm}$ using a Bio-Tek ELx800 microplate reader (BioTek Instrument Inc., USA).

The microbial activity in each microplate was expresses as the average well-colour development (AWCD) and determined according to Garland and Mills [30] as follows:

$\mathrm{AWCD}=\sum \frac{\mathrm{OD}_{i}}{31}$

where $\mathrm{OD}_{i}$ is the optical density at $590 \mathrm{~nm}$ of a substrate $i$ corrected subtracting the blank well values. Furthermore, the biomixture diversity index was calculated according to Fang et al. [29] as follows:

Shannon-Weaver index $H=\Sigma p_{i}\left(\ln p_{i}\right)$ Shannon-Evenness index $E$

$$
=\frac{H^{\prime}}{\ln S}
$$

where $p_{i}$ is the proportional colour development of the $i$ th well over the total colour development of all the wells and S (substrate utilisation richness) is the number of wells with a colour development.

\subsection{Cell enumeration}

The total number of cultivable bacteria, fungi and actinomycetes were counted in the treated and control biomixture. Biomixture samples ( $10 \mathrm{~g}$ d.w.) were placed in Erlenmeyer flasks containing $90 \mathrm{~mL}$ of saline buffer $(0.85 \% \mathrm{NaCl})$ and shaken at $250 \mathrm{rpm}$ and at $25^{\circ} \mathrm{C}$ for $1 \mathrm{~h}$ to ensure homogeneous dispersion of the soil particles. After $30 \mathrm{~min}$, the clear supernatant was used for serial dilutions $\left(10^{-4}-10^{-7}\right)$ and spread onto plate count agar (PCA) media (Difco Laboratories) containing cycloheximide $\left(100 \mathrm{mg} \mathrm{L}^{-1}\right)$ for the determination of the total cultivable bacteria, Rose Bengal-Streptomycin Agar (Oxoid Ltd., UK) for the determination of cultivable fungi and Bacto-Actinomycete Isolation agar (Difco) for the determination of cultivable actinomycetes. The plates were incubated at $30^{\circ} \mathrm{C}$ for 48 and $72 \mathrm{~h}$ for bacteria and actinomycetes, respectively, and at $25^{\circ} \mathrm{C}$ for $72 \mathrm{~h}$ for fungi. All results were expressed as colony forming units (CFU) per $\mathrm{mL}$.

\section{7. $P C R-D G G E$}

The total DNA of the microbial community was extracted from the biomixture $(0.4 \mathrm{~g})$ of each glass container established in Section 2.3 at $0,10,30,40,60,70$ and $90 \mathrm{~d}$ using the NucleoSpin Soil DNA Isolation Kit (Macherey-Nagel. GmbH \& Co., Germany) according manufacturer instructions.

The bacterial DNA was amplified with primers F341-GC and R534 [31], which target the 16S rRNA gene. Positive (Pseudomonas spp.) and negative controls were run for every set of PCRs. ITS regions of the fungal rRNA gene were amplified using the primers ITS3-GC and ITS4 [32]. Positive (Anthracophyllum discolor) and negative controls were run for every set of PCRs. Actinomycetes rRNA fragments were amplified by nested-PCR. To amplify the 16S rRNA gene from actinomycetes, the F243 primer was used with the reverse primer R1378 [33]. One $\mu \mathrm{L}$ of the obtained PCR products (first PCR round) was used as a template for a second PCR using the primers F341-GC and R534 [31]. Positive (Streptomyces spp.) and negative controls were used. All PCR conditions are available as supplementary material

PCR products from bacteria, fungi and actinomycetes were subject to DGGE analysis using an omniPAGE-DGGE (Cleaver Scientific,
Warwickshire, UK). An $8 \%(\mathrm{w} / \mathrm{v})$ polyacrylamide gel containing a linear denaturing gradient between 40-65\% (for bacteria), 30-70\% (for fungi) and 30-60\% (for actinomycetes) of urea and formamide was prepared using a GM-100 Linear Gradient Maker (CBS Scientific, UK). Twenty $\mu \mathrm{L}$ of the PCR products were loaded onto the gel and the electrophoresis was run for $17 \mathrm{~h}$ at $60 \mathrm{~V}$ at $60^{\circ} \mathrm{C}$. After electrophoresis, the gels were silver-stained.

\subsection{Analysis of microbial communities structure}

The cluster analysis of DGGE banding profiles was carried out using the Phoretix 1D analysis software (Nonlinear Dynamics, Durham, USA). The similarity in the profiles of the bands was calculated on the basis of the Pearson correlation coefficient with the UPGMA (Unweighted Pair Group Method with Arithmetic Mean) clustering algorithm. Based on the matrix obtained from Phoretix 1D analysis, the changes in the presence (or absence) and abundance of bacterial groups were analysed by non-metric multidimensional scaling (MDS) using PRIMERv6 (http://www.primer-e.com/demo/demo.htm) with Bray-Curtis similarity index and used to estimate the bacterial diversity by Shannon-Wiener index as described by Yang et al. [34].

\subsection{Pesticides analysis}

ATZ was measured by HPLC using a Merck Hitachi L-2130 pump, a Rheodyne 7725 injector with a $20 \mu \mathrm{L}$ loop and a Merck Hitachi L2455 diode array detector. Separation was achieved using a C18 column (Chromolit RP-18e, $5 \mu \mathrm{m} \times 4.6 \mathrm{~mm} \times 100 \mathrm{~mm}$ ). Eluent $\mathrm{A}$ was ammonium acetate $(1 \mathrm{mM})$ and eluent $B$ was acetonitrile. The flow rate was set at $1.0 \mathrm{~mL} \mathrm{~min}^{-1}$, with $0-10 \mathrm{~min}$ in an isocratic mode. The column temperature was maintained at $30^{\circ} \mathrm{C}$. The detector was set at $222 \mathrm{~nm}$ for the data acquisition. Instrument calibrations and quantification were performed against pure ATZ reference standards $\left(0.1-10 \mathrm{mg} \mathrm{L}^{-1}\right)$.

\subsection{Statistical analysis of data}

Experiments were conducted using three independent replicates. Data were subjected to a one-way analysis of variance (ANOVA) and the averages were compared by Duncan's multiple range tests with a level of 0.95 .

\section{Results and discussion}

\subsection{Degradation of ATZ after repeated applications in the biomixture}

The ATZ removal efficiency in the biomixture was high, i.e., $96 \%$, $78 \%$ and $96 \%$ following the first, second and third successive application, after 30, 60 and $90 \mathrm{~d}$ respectively (Fig. 1). ATZ degradation has been previously studied in the soil, and successive applications of ATZ were shown to enhance its degradation by soil microorganisms [35]. Rapid pesticide degradation has been also observed in biobed system when pesticide-primed material was used in the biomixture [36]. In addition, Vischetti et al. [9] reported that successive applications of metalaxyl on a compost based biomixture resulted in the rapid degradation of the target compound after three applications. However, in this study successive ATZ applications not showed an increase of ATZ degradation in the biomixture used in this study. In fact, after the second application of ATZ, the degradation efficiency slightly decreased (from $96 \%$ to $78 \%$ ), but the system was able to recover and show a positive performance in the 3rd ATZ application, with degradation values of approximately $95 \%$. 


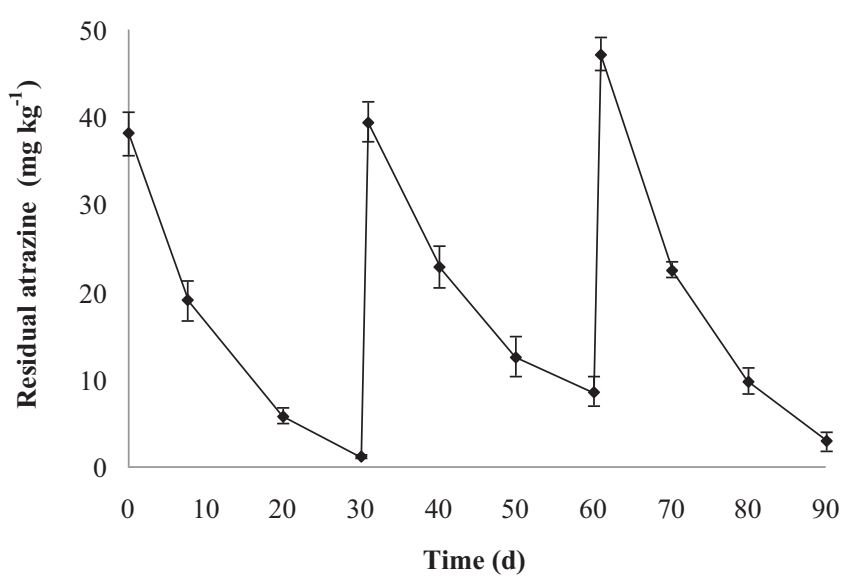

Fig. 1. Residual atrazine in the biomixture after three repeated applications at $40 \mathrm{mg} \mathrm{kg}^{-1}$ and $90 \mathrm{~d}$ of incubation. Error bars represent the standard error of mean of three replicates $(n=3)$.

\subsection{Enzyme activities}

The results for the different enzyme activities measured in the biomixture during the three successive applications of ATZ are shown in Fig. 2. The levels of phosphorus cycling enzymes, acid and alkaline phosphatases, fluctuated during the 90 day incubation (Fig. 2a and b). Acid phosphatase activity ranged between 2 and $9 \mu \mathrm{g} \mathrm{PNFg}^{-1} \mathrm{~h}^{-1}$ in both the ATZ contaminated biomixture and the control assay (Fig. 2a). A negative effect on acid phosphatase activity was observed in the contaminated samples immediately after ATZ application when compared to the control $(P<0.05)$. Nevertheless, the levels of acid phosphatase activity recovered shortly after $1 \mathrm{st}$, 2nd and 3rd ATZ application, which suggests an adaptive response of the microbial communities in the biomixture. Alkaline phosphatase activity, over the treatment time, ranged between 1 and $4 \mu \mathrm{gNFg}^{-1} \mathrm{~h}^{-1}$ (Fig. 2b), and contrary to what was observed with acid phosphatase activity, there was an increase in alkaline phosphatase activity compared to the control $(P<0.05)$ after 1 st, 2nd and 3rd ATZ application. A similar effect was described by Van Dyk and Pletschke [37], in which some pesticides have a positive effect on alkaline phosphatase activity in soil. Furthermore, Perucci and Scarponi [38] reported that alkaline phosphatase activity was increased by ATZ in soil. In another work, Sofo et al. [39] reported that application of four sulphonylureas herbicides in soil at highest doses showed an enhancing effect in both alkaline and acid phosphatase activities. However, the differences in the response of phosphatase activities could be due to the chemical nature of the pesticides or to differences in the physical, chemical or microbiological properties of the soil used in the studies.
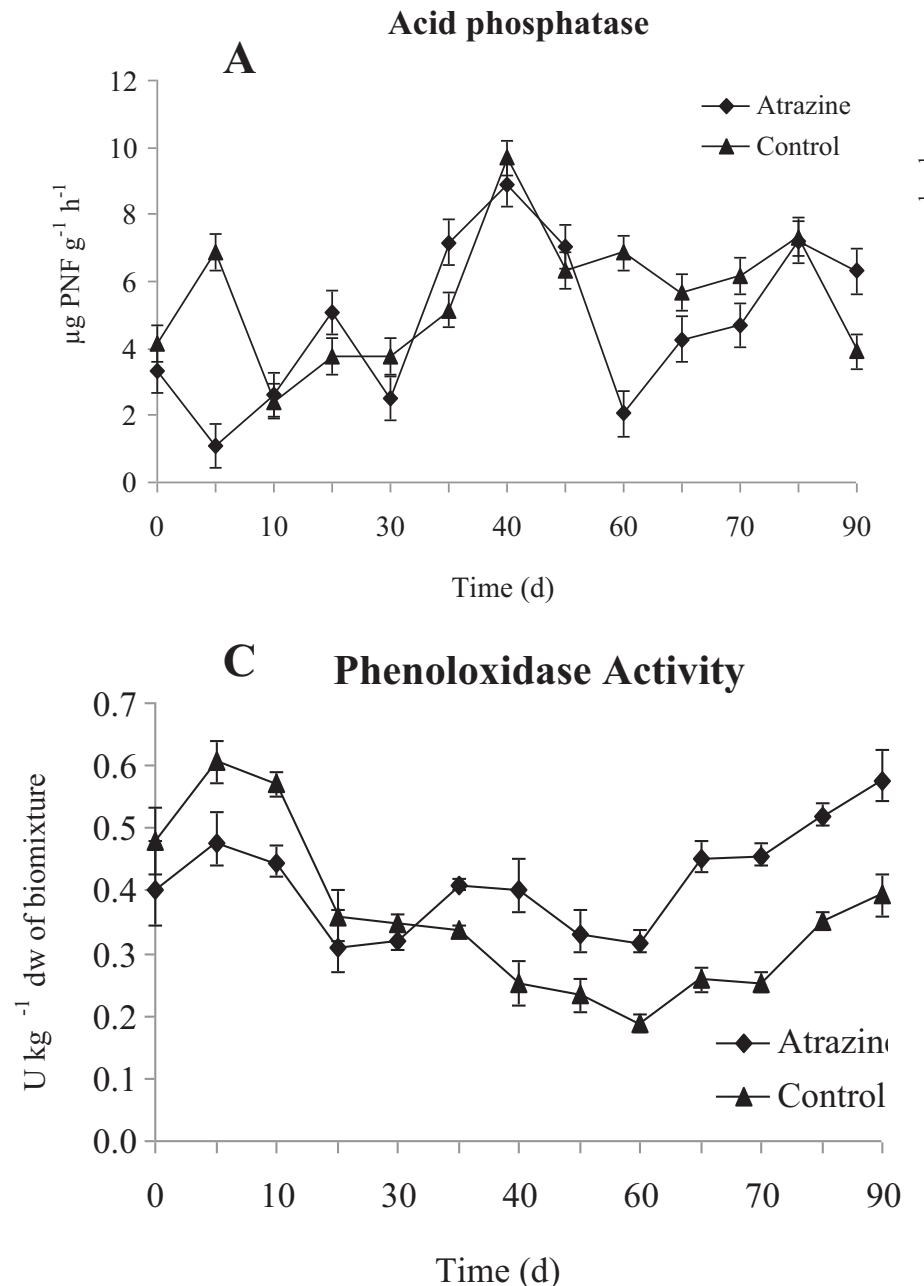

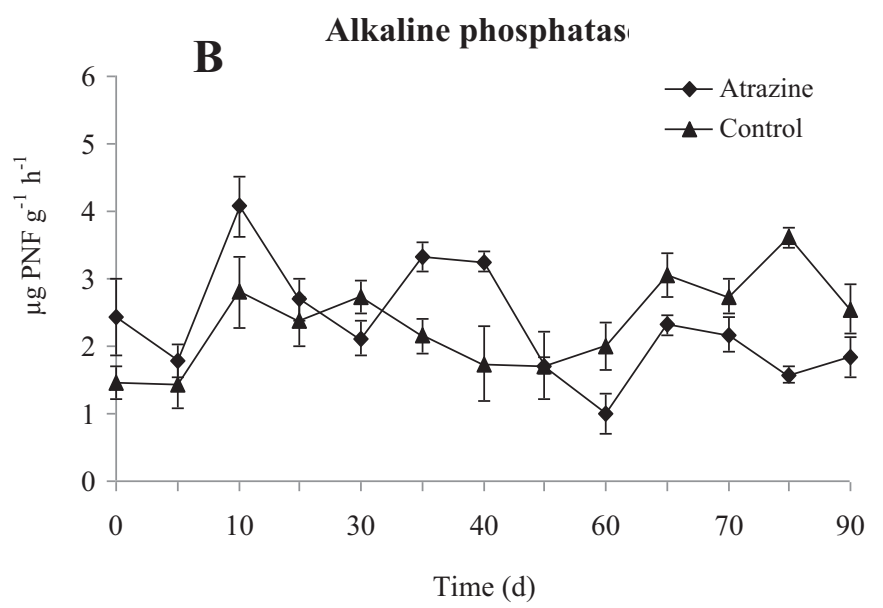

D Dehydrogenas

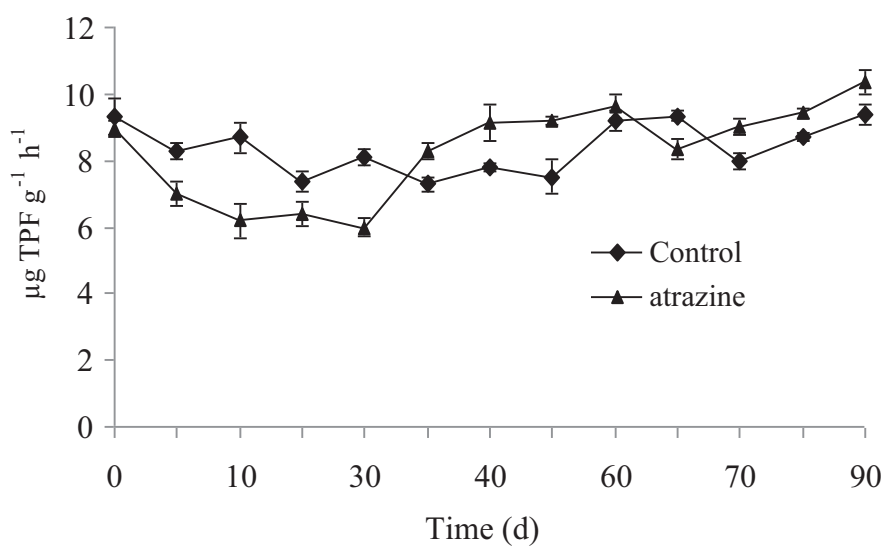

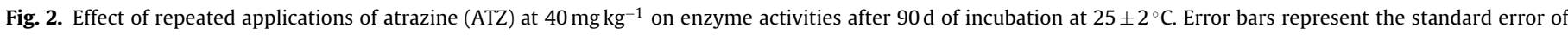
mean of three replicates $(n=3)$. 

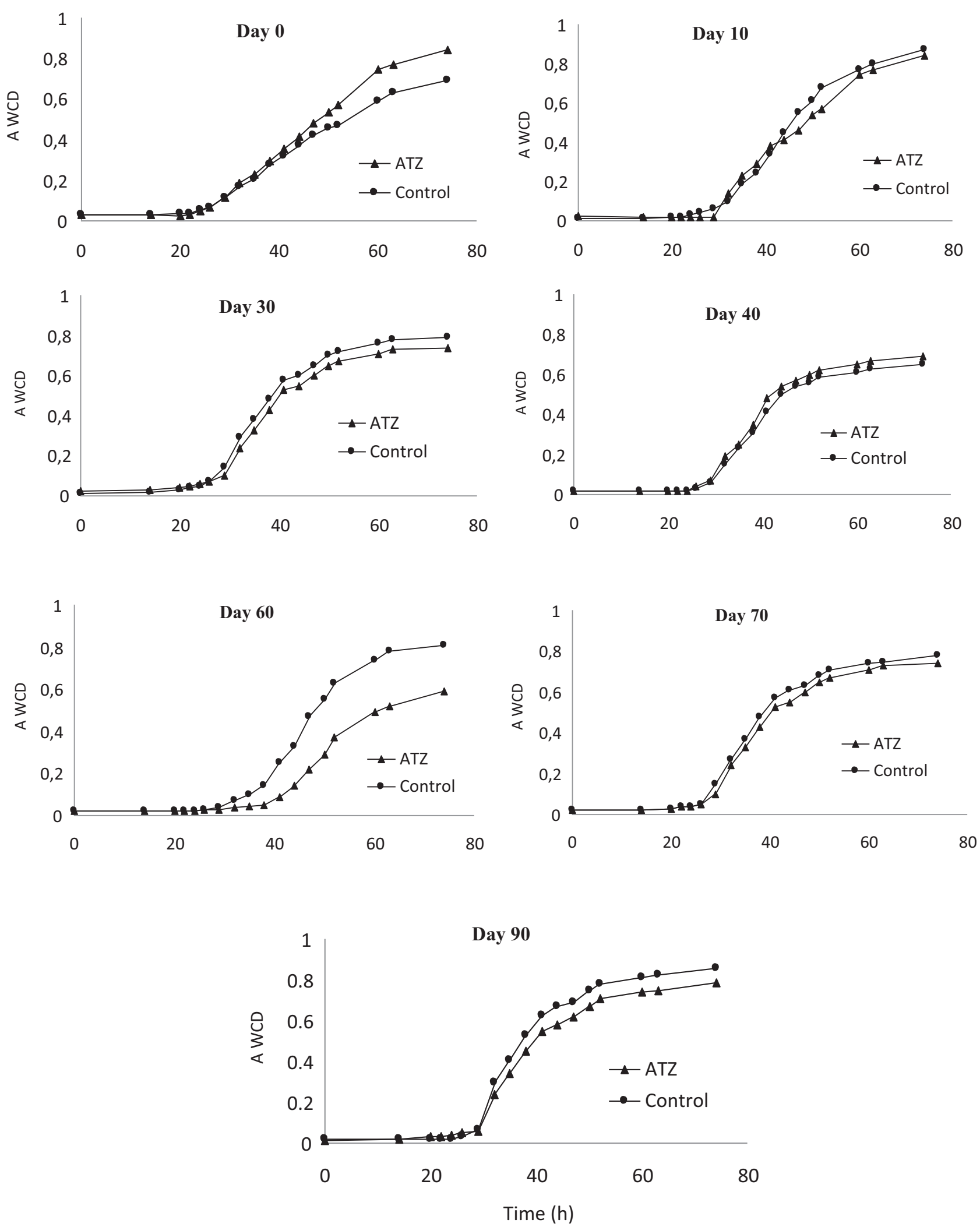

Fig. 3. Average well colour development (AWCD) of biomixture samples at different sampling times.

ATZ application significantly $(P<0.05)$ diminishes the phenoloxidase activity during the first $30 \mathrm{~d}$ of the incubation (1st ATZ application) compared to the control (Fig. 2c). However, phenoloxidase activity was increased $\left(0.55 \mathrm{UL}^{-1}\right)$ when compared to the control $\left(0.37 \mathrm{UL}^{-1}\right)$ after the 2 nd and 3rd ATZ application to the biomixture (day 30 and 60). Phenoloxidase activity has been reported as the most important biological activity for pollutant degradation in soil $[40,41]$ and in the biomixture of biobed systems [2]. Our results suggest that ATZ degradation might be linked to extracellular phenoloxidases produced by fungi present in the 
Table 1

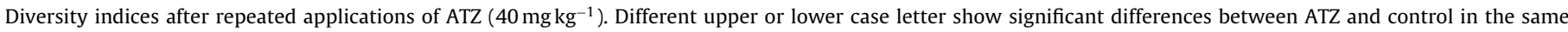
sampling point or between different sampling points within the same treatment respectively. Mean values $(n=3)$ with Duncan test $(P \leq 0.05)$.

\begin{tabular}{|c|c|c|c|c|}
\hline \multirow[t]{2}{*}{ Time $(\mathrm{d})$} & \multicolumn{2}{|l|}{ Shannon's (H) } & \multicolumn{2}{|l|}{ Evenness (E) } \\
\hline & Atrazine & Control & Atrazine & Control \\
\hline 0 & $3.18 \pm 0.02 \mathrm{Aa}$ & $3.14 \pm 0.03 \mathrm{Aa}$ & $0.95 \pm 0.01 \mathrm{Aab}$ & $0.94 \pm 0.01 \mathrm{Aab}$ \\
\hline 10 & $2.89 \pm 0.05 \mathrm{Ab}$ & $2.30 \pm 0.05 \mathrm{Bd}$ & $0.95 \pm 0.02 \mathrm{Aab}$ & $0.93 \pm 0.01 \mathrm{Abc}$ \\
\hline 30 & $3.17 \pm 0.02 \mathrm{Aa}$ & $3.09 \pm 0.02 \mathrm{Aa}$ & $0.95 \pm 0.01 \mathrm{Aab}$ & $0.95 \pm 0.01 \mathrm{Aab}$ \\
\hline 40 & $2.88 \pm 0.06 \mathrm{Ab}$ & $2.81 \pm 0.04 \mathrm{Ab}$ & $0.92 \pm 0.01 \mathrm{Ab}$ & $0.91 \pm 0.03 \mathrm{Ac}$ \\
\hline 60 & $2.60 \pm 0.06 \mathrm{Ac}$ & $2.88 \pm 0.02 \mathrm{Ac}$ & $0.91 \pm 0.01 \mathrm{Aa}$ & $0.96 \pm 0.01 \mathrm{Aa}$ \\
\hline 70 & $2.98 \pm 0.12 \mathrm{Bb}$ & $2.68 \pm 0.05 \mathrm{Aa}$ & $0.97 \pm 0.04 \mathrm{Ab}$ & $0.96 \pm 0.02 \mathrm{Aab}$ \\
\hline 90 & $3.06 \pm 0.13 \mathrm{Aa}$ & $2.60 \pm 0.13 \mathrm{Ba}$ & $0.95 \pm 0.01 \mathrm{Aab}$ & $0.97 \pm 0.01 \mathrm{Aab}$ \\
\hline
\end{tabular}

biomixture, especially during the last $30 \mathrm{~d}$ of incubation. Nevertheless, although phenoloxidase activity increased immediately after the 2nd ATZ application (Fig. 2c), degradation efficiency is low (78\%) in this period (Fig. 1). ATZ degradation in soil by fungi and bacteria has been well reported [42-45]. Therefore, these results suggest that others degradation mechanisms or enzyme activities involved in ATZ degradation and not evaluated here as cellobiose dehydrogenase [44] could be affected in the biomixture after repeated pesticide application.

The observed dehydrogenase levels did not show marked fluctuation patterns, with activities ranging from 6 to $10 \mu \mathrm{gg}^{-1} \mathrm{~h}^{-1}$ and $7-9 \mu \mathrm{gg}^{-1} \mathrm{~h}^{-1}$ in the contaminated biomixture and the control, respectively (Fig. 2e). A significant $(P<0.05)$ decrease $(30 \%)$ in the activity was observed within the first $20 \mathrm{~d}$ after ATZ application. However, the activity recovered to the initial values after the second application of ATZ and was slightly increased after the third application. Moreno et al. [46] found that dehydrogenase activity was stimulated with high doses $\left(1000 \mathrm{mg} \mathrm{kg}^{-1}\right)$ of ATZ in the soil. Comparable results were observed by Radivojevic et al. [47], who found that ATZ at 8,40 and $80 \mathrm{mg} \mathrm{kg}^{-1}$ caused an inhibitory effect on dehydrogenase activity in the soil, but a recovery was observed after $60 \mathrm{~d}$ of incubation.

Overall, the enzyme activity levels in the biomixture after 1st, 2nd and 3rd ATZ application ( $40 \mathrm{mg} \mathrm{kg}^{-1}$ ) suggest that the microbial response to ATZ applications occurs relatively fast, and this could be related to the diminished effects of the pesticide tested, due to degradation processes and/or to the adaptation of the microbial communities to ATZ.

\subsection{Community level physiological profiles (CLPP)}

The community level physiological profiles in the ATZ treated biomixtures were analysed using the BiologEcoplate ${ }^{\mathrm{TM}}$. Assays were carried out over a $78 \mathrm{~h}$ incubation period (Fig. 3). A slight increase in the average well colour development (AWCD) was observed in ATZ treated samples at an early stage of treatment (Fig. 3, day 0) in relation to the control. However, after this time not significant $(P>0.05)$ differences were observed (Fig. 3, day 10 , 30 and 40). Conversely, a significant inhibitory effect on the AWCD was observed immediately following the third application of ATZ in the biomixture (Fig. 3, day 60). However on day 70, the system had already recovered the control level (Fig. 3, day 70). Fang et al. [29] reported an initial negative effect on the AWCD after chlorpyrifos application to the soil. Nevertheless, the AWCD recovered after $35 \mathrm{~d}$, and the biomix showed higher AWCD values than the control, which indicates an improvement in microbial activity. In this study, the results showed that ATZ caused a slightly negative effect at day 0 and a significant decrease in the AWCD after $60 \mathrm{~d}$ of incubation. Finally, by the end of the experiment ( $90 \mathrm{~d}$ of incubation), the AWCD was recovered; although no enhancement of the microbial oxidative capacity was observed. These results are consistent with the results found in the degradation assay, where no accelerated degradation was observed after three successive applications of ATZ. On the other hand, the results from BiologEcoplate ${ }^{\mathrm{TM}}$ showed a similar trend to the enzyme activities, where an initial decline is observed followed by a recovery of biological activity.

The diversity indices Shannon's $(\mathrm{H})$ and Shannon's evenness (U) were used to evaluate richness and homogeneity of the microbial populations present in the biomixture, respectively. The changes in microbial diversity indices after three successive applications of ATZ are summarised in Table 1 . At d 0, 30, 40 and 60, the control and treatment samples were similar $(P>0.05)$ in microbial richness $(\mathrm{H})$, demonstrating an absence of an immediate effect of the ATZ application on the microbial richness in the biomixture. However, a significant difference $(P<0.05)$ in bacterial richness between the treatment and control samples was observed at $\mathrm{d} 10$, 70 and 90 . Table 1 shows an enhanced bacterial richness after ATZ application at this $\mathrm{d}$, suggesting a possible adaptation and/or tolerance of microorganisms to the pesticide. Similarly, Fang et al. [29] described that higher Shannon values indicate a balance between different types of microorganisms in the biomixture, which could be disturbed by the growth of specific microorganisms that adapted to ATZ. Conversely, the addition of ATZ at $40 \mathrm{mg} \mathrm{kg}^{-1}$ in three successive applications did not caused changes in microorganism homogeneity (U) when compared to the control. Different results were reported by Fang et al. [29], where the application of chlorpyrifos to the soil caused a decrease in microbial homogeneity at an early stage after chlorpyrifos application and lasted until the end of the experiment. However, this difference could be explained by the chemical structure and the toxicity of the studied pesticide.

Table 2

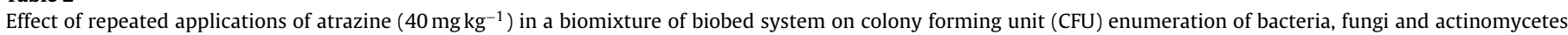
after $90 \mathrm{~d}$ of incubation at $25 \pm 2{ }^{\circ} \mathrm{C}$.

\begin{tabular}{|c|c|c|c|c|c|c|c|c|}
\hline \multicolumn{9}{|l|}{ Time (days) } \\
\hline Soil microorganism (CFU) & Treatment & 0 & 10 & 30 & 40 & 60 & 70 & 90 \\
\hline \multirow[t]{2}{*}{ Bacteria $\left(\times 10^{6} / \mathrm{g} \mathrm{dw}\right)$} & Control & $15.5 \pm 1.0 \mathrm{a}$ & $12.5 \pm 2.0 \mathrm{a}$ & $27.5 \pm 4.4 \mathrm{a}$ & $43.1 \pm 3.0 \mathrm{a}$ & $38.1 \pm 2.7 \mathrm{a}$ & $29.5 \pm 1.0 \mathrm{a}$ & $35.4 \pm 3.6 \mathrm{a}$ \\
\hline & Atrazine & $14.5 \pm 1.7 \mathrm{a}$ & $12.5 \pm 1.2 \mathrm{a}$ & $20.5 \pm 3.2 b$ & $45.7 \pm 4.1 \mathrm{a}$ & $39.1 \pm 1.0 \mathrm{a}$ & $28.5 \pm 1.5 \mathrm{a}$ & $31.2 \pm 2.8 \mathrm{a}$ \\
\hline \multirow[t]{2}{*}{ Fungi ( $\left.\times 10^{5} / \mathrm{g} \mathrm{dw}\right)$} & Control & $3.4 \pm 0.1 \mathrm{a}$ & $3.5 \pm 0.4 \mathrm{a}$ & $7.8 \pm 1.2 \mathrm{a}$ & $6.5 \pm 1.0 \mathrm{a}$ & $6.9 \pm 0.5 \mathrm{a}$ & $6.5 \pm 1.9 \mathrm{a}$ & $7.4 \pm 1.4 \mathrm{a}$ \\
\hline & Atrazine & $2.1 \pm 0.2 b$ & $3.9 \pm 1.0 \mathrm{a}$ & $7.5 \pm 1.0 \mathrm{a}$ & $5.8 \pm 0.8 b$ & $5.5 \pm 0.2 b$ & $5.2 \pm 1.1 \mathrm{~b}$ & $6.9 \pm 0.6 a$ \\
\hline \multirow{2}{*}{$\begin{array}{l}\text { Actinomycetes } \\
\left(\times 10^{5} / \mathrm{g} \mathrm{dw}\right)\end{array}$} & Control & $17.4 \pm 1.2 \mathrm{a}$ & $33 \pm 4.0 \mathrm{a}$ & $21.0 \pm 2.4 \mathrm{a}$ & $18.5 \pm 1.7 \mathrm{a}$ & $41.0 \pm 6.4 \mathrm{a}$ & $24.5 \pm 5.1 \mathrm{a}$ & $23.5 \pm 1.2 \mathrm{a}$ \\
\hline & Atrazine & $15.1 \pm 2.0 \mathrm{a}$ & $30 \pm 3.0 \mathrm{a}$ & $24.0 \pm 1.4 \mathrm{a}$ & $19.5 \pm 1.5 \mathrm{a}$ & $28.0 \pm 2.4 b$ & $20.5 \pm 1.7 \mathrm{a}$ & $22.4 \pm 1.7 \mathrm{a}$ \\
\hline
\end{tabular}




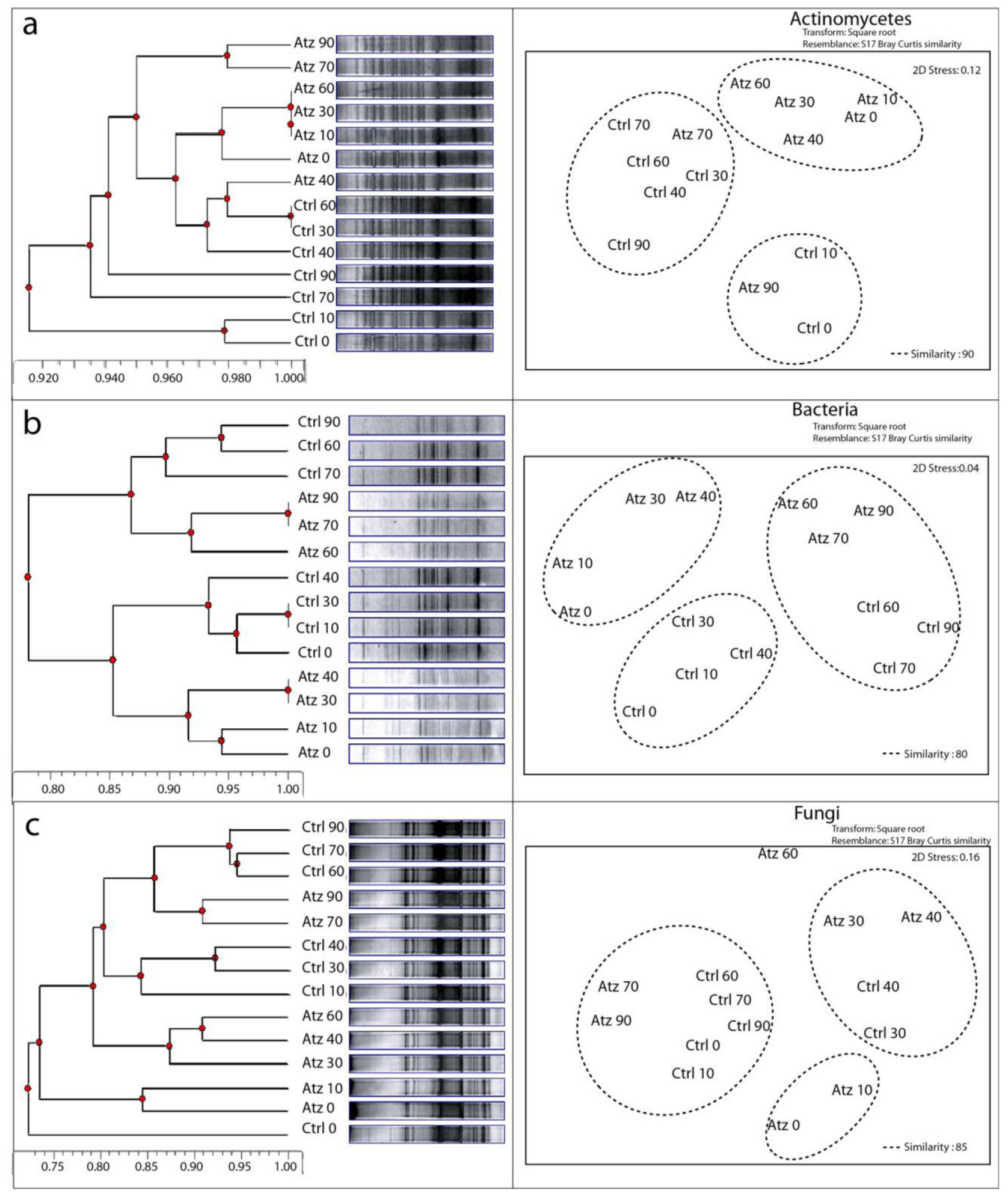

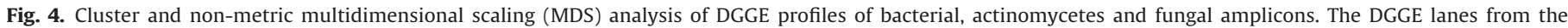
contaminated biomixture and the control were denoted as ATZ 0 to ATZ 90 and Ctrl 0 to Ctrl 90, respectively, where the number indicates the sampling day.

\subsection{Cell enumeration}

The effects on CFUs of cultivable bacteria, fungi and actinomycetes after three successive applications of ATZ at $40 \mathrm{mg} \mathrm{kg}^{-1}$ are shown in Table 2 . No significant differences $(P>0.05)$ in bacterial CFUs were found with respect to the control in all time points. Conversely, the effect of ATZ applications on fungi CFUs showed a significant reduction $(P<0.05)$ immediately after each application of ATZ when compared to the control. This effect suggests that the fungal population could be more sensitive to the presence of ATZ treatment in the biomixture. However, the amounts of fungal CFUs in the control and the treatment samples tended to be similar at the end of the assay. Finally, the effect of ATZ applications on the actinomycete CFUs was similar to that for bacterial 
populations (Table 2$)$. However, a significant decrease $(P<0.05)$ of the actinomycetes CFUs $\left(28 \times 10^{5} \mathrm{~g} \mathrm{dw}\right)$ was observed after the $3 \mathrm{rd}$ ATZ application (day 60) compared to the control $\left(41 \times 10^{5} \mathrm{~g} \mathrm{dw}\right)$. Although, similar actinomycete CFUs were observed in the control and the treatment.

Few studies have evaluated the impact of pesticides on culturable microorganisms in the biomixture of a biobed system. However, comparable results were reported by Coppola et al. [20]. They found that successive fungicide application in the biomixture of a biobed system did not cause relevant effects on total culturable bacteria, but a slight reduction was observed in cultivable fungal communities. It is expected that fungicides caused negative effects on fungi. However, in this work culturable fungi were notoriously affected by the presence of an herbicide. Therefore, specific effects of ATZ must be evaluated in more details in future works. Chu et al. [48] reported that the insecticide chlorpyrifos caused inhibitory effects on bacterial, fungal and actinomycetes communities in soil during the initial periods after pesticide application, but they recovered by the end of the experiment. According to this, is interesting to note that different pesticides can cause negative effects on a particular class of microorganism. Therefore, although studies with pesticide mixture are most representative of field condition, responses caused by a single pesticide are also necessary to understand individual effects caused by the pesticides on microbial communities.

\subsection{DGGE profiles}

Ours results revealed a similar intense of DGGE bands in all the analysed samples, indicating the presence of a large number of equally abundant ribotypes in both treated and untreated biomixtures. The actinomycetes ribotype composition was similar in all the samples (greater than 92\%) (Fig. 4a), and only small differences in Ctrl 0 and Ctrl 10 samples, which grouped aside from all the other samples, as shown the cluster analysis. The MDS analysis did not show differences between 3rd ATZ applications and Ctrl (90\% similarity). This finding suggests that if there is an effect of ATZ on actinomycetes communities, it is only observed shortly after pesticide application. These results are in accordance with the results observed with cultivable actinomycetes, wherein no significant differences were observed between the biomixture contaminated with ATZ and the control.

Clustering of the bacterial communities revealed the existence of two major groups with a similarity of $78 \%$. One group is comprised of both the treatment (ATZ) and the control (Crtl) samples between 0 and $40 \mathrm{~d}$ and the second group is comprised of both the ATZ and Crtl samples between 60 and $90 \mathrm{~d}$ with a similarity 90 among. The MDS analysis revealed that the chronologic applications of ATZ produce shortly changes on bacterial communities with respect to Ctrl (80\% similarity) in the same application period (Fig. $4 \mathrm{~b}$ ). This result suggests that there were changes in the bacterial communities in the biomixture after $40 \mathrm{~d}$ of incubation. However, changes were not related with pesticide application.

In relation of DGGE patterns for fungal communities are shown in Fig. 4c. DGGE patterns representing the fungal communities in the biomixture samples showed high similarity indices (>85\%). Furthermore, the MDS analysis shown no difference between treated and untreated samples of communities structure, however can be observed differences associated with the pesticide application times (Fig. 4c). In addition, Shannon-Wiener index revealed that the treatments of ATZ application had no effect on microbial diversity evaluated in PCR-DGGE analysis.

Overall the results obtained by DGGE were in accordance with those obtained by BiologEcoplate ${ }^{\mathrm{TM}}$, and demonstrated that bacterial and fungal populations in the ATZ contaminated biomixture were rather stable. Both methods showed that the fingerprint of the microbial populations in the treated and untreated biomixtures did not significantly differ from each other. Also, and considering microbial abundance, no significant differences $(P>0.05)$ in viable cell count were observed when comparing ATZ and Ctrl biomixture samples (after $90 \mathrm{~d}$ of incubation). Recently, Marinozzi et al. [5] also showed that the contamination of biomixtures with the fungicides azoxystrobn, fludioxonil and pencanazole had only a transient effect on the microbial communities, with a full recovery of the microbial indices $60 \mathrm{~d}$ post-application. Similar observations have been previously reported by Coppola et al. [20] after repeated applications of different vineyard fungicides (azoxystrobin, fludioxonil, penconazole, dimethomorph, metalaxyl, and cyprodinil). Changes in the microbial communities in the biomixture, resulting from the application of these fungicides, were transitory and disappeared after $112 \mathrm{~d}$. Interestingly, Sniegowski et al. [10] reported that changes in overall microbial communities in biobed revealed by DGGE were attributed to other factors more than pesticide application. However, changes in microbial communities related with pesticide application were detected when specific target bacterial genera were analysed. Overall, results evidence the resilience and robustness of microbial communities in biomixture towards the presence of different fungicides.

\section{Conclusion}

The results obtained demonstrate that peat based biomixture could support and degrade successive ATZ applications, even when a high ATZ concentration ( $40 \mathrm{mg} \mathrm{kg}^{-1}$ ) was added. Viable cell count, carbon source utilisation profiles and DGGE analysis showed that minor changes occur in the microbial communities after an ATZ application. Biochemical activities were susceptible to pesticide exposure, and the enzyme activities evaluated can be inhibited or stimulated by ATZ. However, the negative effects were transient and recovered in time after pesticide application. The results reported here not only reinforce the idea of a large degradation capacity of the biomixture but also demonstrate the robustness of this biological system from a microbiological viewpoint.

\section{Acknowledgements}

This work was supported by FONDECYT project No 11100236.

\section{Appendix A. Supplementary data}

Supplementary data associated with this article can be found, in the online version, at http://dx.doi.org/10.1016/j.jhazmat. 2013.05.059.

\section{References}

[1] L. Torstensson, M.d.P. Castillo, Use of biobeds in Sweden to minimize environmental spillages from agricultural spraying equipment, Pestic. Outlook 8(1997) 24-27.

[2] M.d.P. Castillo, L. Torstensson, J. Stenstrom, Biobeds for environmental protection from pesticide use - a review, J. Agric. Food. Chem. 56 (2008) 6206-6219.

[3] E. Karanasios, N.G. Tsiropoulos, D.G. Karpouzas, C. Ehaliotis, Degradation and adsorption of pesticides in compost-based biomixtures as potential substrates for biobeds in Southern Europe, J. Agric. Food Chem. 58 (2010) 9147-9156.

[4] E. Karanasios, N.G. Tsiropoulos, D.G. Karpouzas, U. Menkissoglu-Spiroudi, Novel biomixtures based on local Mediterranean lignocellulosic materials: evaluation for use in biobed systems, Chemosphere 80 (2010) 914-921.

[5] M. Marinozzi, L. Coppola, E. Monaci, D. Karpouzas, E. Papadopoulou, U. Menkissoglu-Spiroudi, C. Vischetti, The dissipation of three fungicides in a biobed organic substrate and their impact on the structure and activity of the microbial community, Environ. Sci. Pollut. Res. 20 (2013) 2546-2555.

[6] L. Coppola, M.d.P. Castillo, E. Monaci, C. Vischetti, Adaptation of the biobed composition for chlorpyrifos degradation to southern Europe conditions, J. Agric. Food Chem. 55 (2007) 396-401. 
[7] P. Fogg, A.B.A. Boxall, A. Walker, A.A. Jukes, Pesticide degradation in a 'biobed' composting substrate, Pest. Manag. Sci. 59 (2003) 527-537.

[8] G.R. Tortella, O. Rubilar, M.d.P. Castillo, M. Cea, R. Mella-Herrera, M.C. Diez, Chlorpyrifos degradation in a biomixture of biobed at different maturity stages, Chemosphere 88 (2012) 224-228.

[9] C. Vischetti, E. Monaci, A. Cardinali, C. Casucci, P. Perucci, The effect of initial concentration, co-application and repeated applications on pesticide degradation in a biobed mixture, Chemosphere 72 (2008) 1739-1743.

[10] K. Sniegowski, K. Bers, J. Ryckeboer, P. Jaeken, P. Spanoghe, D. Springael, Robust linuron degradation in on-farm biopurification systems exposed to sequential environmental changes, Appl. Environ. Microbiol. 77 (2011) 6614-6621.

[11] K. Sniegowski, K. Bers, K. Van Goetem, J. Ryckeboer, P. Jaeken, P. Spanoghe, D. Springael, Improvement of pesticide mineralization in on-farm biopurification systems by bioaugmentation with pesticide-primed soil, FEMS Microbiol. Ecol. 76 (2011) 64-73.

[12] K. Bers, K. Sniegowski, R. De Mot, D. Springael, Dynamics of the linuron hydrolase liba gene pool size in response to linuron application and environmental perturbations in agricultural soil and on-farm biopurification systems, Appl. Environ. Microbiol. 78 (2012) 2783-2789.

[13] N.H. Spliid, A. Helweg, K. Heinrichson, Leaching and degradation of 21 pesticides in a full-scale model biobed, Chemosphere 65 (2006) 2223-2232.

[14] M. Omirou, P. Dalias, C. Costa, C. Papastefanou, A. Dados, C. Ehaliotis, D.G. Karpouzas, Exploring the potential of biobeds for the depuration of pesticidecontaminated wastewaters from the citrus production chain: laboratory, column and field studies, Environ. Pollut. 166 (2012) 31-39.

[15] K. Johnsen, C.S. Jacobsen, V. Torsvik, J. Sorensen, Pesticide effects on bacterial diversity in agricultural soils - a review, Biol. Fert. Soils. 33 (2001) 443-453.

[16] A. Kalia, S.K. Gosal, Effect of pesticide application on soil microorganisms, Arch. Agron. Soil Sci. 57 (2011) 569-596.

[17] A. Chowdhury, S. Pradhan, M. Saha, N. Sanyal, Impact of pesticides on soil microbiological parameters and possible bioremediation strategies, Indian J. Microbiol. 48 (2008) 114-127.

[18] G. Imfeld, S. Vuilleumier, Measuring the effects of pesticides on bacterial communities in soil: a critical review, Eur. J. Soil. Biol. 49 (2012) 22-30.

[19] E. Karanasios, N.G. Tsiropoulos, D.G. Karpouzas, On-farm biopurification systems for the depuration of pesticide wastewaters: recent biotechnological advances and future perspectives, Biodegradation 23 (2012) 787-802.

[20] L. Coppola, F. Comitini, C. Casucci, V. Milanovic, E. Monaci, M. Marinozzi, M. Taccari, M. Ciani, C. Vischetti, Fungicides degradation in an organic biomixture: impact on microbial diversity, New Biotechnol. 29 (2011) 99-106.

[21] M.M. de Andrea, T.B. Peres, L.C. Luchini, S. Bazarin, S. Papini, M.B. Matallo, V.L.T. Savoy, Influence of repeated applications of glyphosate on its persistence and soil bioactivity, Pesqui. Agropec. Bras. 38 (2003) 1329-1335.

[22] N.D. Jablonowski, S. Koppchen, D. Hofmann, A. Schaffer, P. Burauel, Persistence of C-14-labeled atrazine and its residues in a field lysimeter soil after 22 years, Environ. Pollut. 157 (2009) 2126-2131.

[23] D. Ghosh, K. Dutta, D. Bhattacharyay, P. Sarkar, Amperometric detection of pesticides using polymer electrodes, Environ. Monit. Assess. 119 (2006) 481-489.

[24] R.K. Pandey, R.N. Singh, S. Singh, N.N. Singh, V.K. Das, Acute toxicity bioassay of dimethoate on freshwater airbreathing catfish, Heteropneustes fossilis (Bloch), J. Environ. Biol. 30 (2009) 437-440.

[25] L.E. Casida Jr., Microbial metabolic activity in soil as measured by dehydrogenase determinations, Appl. Environ. Microbiol. 34 (1977) 630-636.

[26] M.A. Tabatabai, J.M. Bremner, Use of p-nitrophenyl phosphate for assay of soil phosphatase activity, Soil Biol. Biochem. 1 (1969) 301-307.

[27] M. d.P. Castillo, J. Stenstrom, P. Ander, Determination of manganese peroxidase activity with 3-methyl-2-benzothiazolinone hydrazone and 3(dimethylamino)benzoic acid, Anal Biochem. 218 (1994) 399-404.

[28] M.d.P. Castillo, L. Torstensson, Effect of biobed composition, moisture, and temperature on the degradation of pesticides, J. Agric. Food Chem. 55 (2007) 5725-5733.
[29] H. Fang, Y.L. Yu, X.Q. Chu, X.G. Wang, X.E. Yang, J.Q. Yu, Degradation of chlorpyrifos in laboratory soil and its impact on soil microbial functional diversity, J Environ. Sci. (China) 21 (2009) 380-386.

[30] J.L. Garland, A.L. Mills, Classification and characterization of heterotrophic microbial communities on the basis of patterns of community-level solecarbon-source utilization, Appl. Environ. Microbiol. 57 (1991) 2351-2359.

[31] G. Muyzer, E.C. Dewaal, A.G. Uitterlinden, Profiling of complex microbialpopulations by denaturing gradient gel-electrophoresis analysis of polymerase chain reaction-amplified genes-coding for 16s ribosomal-RNA, Appl. Environ. Microbiol. 59 (1993) 695-700.

[32] T. White, T. Bruns, S. Lee, J. Taylor, in: M. Innis, D. Gelfand, J. Shinsky, T. White (Eds.), PCR Protocols: A Guide to Methods and Applications, Academic Press, San Diego, 1990, pp. 315-322.

[33] H. Heuer, M. Krsek, P. Baker, K. Smalla, E.M.H. Wellington, Analysis of actinomycete communities by specific amplification of genes encoding 16S rRNA and gel-electrophoretic separation in denaturing gradients, Appl. Environ. Microbiol. 63 (1997) 3233-3241.

[34] Y.J. Yang, R.S. Dungan, A.M. Ibekwe, C. Valenzuela-Solano, D.M. Crohn, D.E. Crowley, Effect of organic mulches on soil bacterial communities one year after application, Biol. Fertil. Soils 38 (2003) 273-281.

[35] S. Houot, E. Topp, A. Yassir, G. Soulas, Dependence of accelerated degradation of atrazine on soil pH in French and Canadian soils, Soil. Biol. Biochem. 32 (2000) 615-625.

[36] T. De Wilde, P. Spanoghe, K. Sniegowksi, D. Ryckeboer, P. Jaeken, D. Springael, Transport and degradation of metalaxyl and isoproturon in biopurification columns inoculated with pesticide-primed material, Chemosphere 78 (2010) 56-60.

[37] J.S. Van Dyk, B. Pletschke, Review on the use of enzymes for the detection of organochlorine, organophosphate and carbamate pesticides in the environment, Chemosphere 82 (2011) 291-307.

[38] P. Perucci, L. Scarponi, Atrazine, alachlor and metolachlor - persistence and phosphatase-activity in a clay-loam soil, Agrochimica 34 (1990) 214-222.

[39] A. Sofo, A. Scopa, S. Dumontet, A. Mazzatura, V. Pasquale, Toxic effects of four sulphonylureas herbicides on soil microbial biomass, J. Environ. Sci. Health B 47 (2012) 653-659.

[40] G. Briceno, G. Palma, N. Duran, Influence of organic amendment on the biodegradation and movement of pesticides, Crit. Rev. Env. Sci. Tech. 37 (2007) 233-271.

[41] M.C. Diez, Biological aspects involved in the degradation of organic pollutants, J. Soil Sci. Plant Nut. 10 (2010) 244-267.

[42] J.K. Struthers, K. Jayachandran, T.B. Moorman, Biodegradation of atrazine by Agrobacterium radiobacter $\mathrm{J} 14 \mathrm{a}$ and use of this strain in bioremediation of contaminated soil, Appl. Environ. Microbiol. 64 (1998) 3368-3375.

[43] L.L. Vibber, M.J. Pressler, G.M. Colores, Isolation and characterization of novel atrazine-degrading microorganisms from an agricultural soil, Appl. Microbiol. Biotechnol. 75 (2007) 921-928.

[44] V.V. Khromonygina, A.I. Saltykova, L.G. Vasil'chenko, Y.P. Kozlov, M.L. Rabinovich, Degradation of the herbicide atrazine by the soil mycelial fungus INBI 2-26(-), a producer of cellobiose dehydrogenase, Prikl. Biokhim. Mikrobiol. 40 (2004) 337-343.

[45] E.D. Rhine, J.J. Fuhrmann, M. Radosevich, Microbial community responses to atrazine exposure and nutrient availability: linking degradation capacity to community structure, Microbial. Ecol. 46 (2003) 145-160.

[46] J.L. Moreno, A. Aliaga, S. Navarro, T. Hernandez, C. Garcia, Effects of atrazine on microbial activity in semiarid soil, Appl. Soil Ecol. 35 (2007) 120-127.

[47] L.J. Radivojevic, S. Gasic, L.J. Santric, R. Stankovic-Kalezic, The impact of atrazine on several biochemical properties of chernozem soil, J. Serb. Chem. Soc. 73 (2008) 951-959.

[48] X.Q. Chu, H. Fang, X.D. Pan, X. Wang, M. Shan, B. Feng, Y.L. Yu, Degradation of chlorpyrifos alone and in combination with chlorothalonil and their effects on soil microbial populations, J. Environ. Sci. (China) 20 (2008) 464-469. 